7. Berger, M. J., LeVeque, R. J. (1990). Stable boundary conditions for Cartesian grid calculations. Computing Systems in Engineering, 1 (2-4), 305-311. doi: https://doi.org/10.1016/0956-0521(90)90016-e

8. Berger, M., Helzel, C. (2012). A Simplified h-box Method for Embedded Boundary Grids. SIAM Journal on Scientific Computing, 34 (2), A861-A888. doi: https://doi.org/10.1137/110829398

9. Ferziger, J. H., Milovan, P., Street, R. L. (2020). Computational Methods for Fluid Dynamics. Springer. doi: https://doi.org/ 10.1007/978-3-319-99693-6

10. Chung, T. J. (2010). Computational Fluid Dynamics. Cambridge University Press. doi: https://doi.org/10.1017/cbo9780511780066

11. Courant, R., Friedrichs, K., Lewy, H. (1967). On the Partial Difference Equations of Mathematical Physics. IBM Journal of Research and Development, 11 (2), 215-234. doi: https://doi.org/10.1147/rd.112.0215

12. Loytsyanskiy, L. G. (2003). Mehanika zhidkosti i gaza. Moscow: Drofa, 840.

13. Bucharskiy, V. L. (2007). Metod sovmestnoy approksimatsii postroeniya raznostnyh shem dlya resheniya uravneniy v chastnyh proizvodnyh. Tehnicheskaya mehanika, 1, 129-138.

14. Woodward, P., Colella, P. (1984). The numerical simulation of two-dimensional fluid flow with strong shocks. Journal of Computational Physics, 54 (1), 115-173. doi: https://doi.org/10.1016/0021-9991(84)90142-6

\begin{abstract}
A new method of reducing the resistance of submarines is presented, which consists in installing special circular recesses on its surface in the stern. It is found that during the movement, in the recesses there is a macro-vortex flow, in which pressure decreases significantly. This phenomenon affects the characteristics of the boundary layer and in general the pressure distribution on the surface of the hull, $i$. e. the resistance of the submarine. Using the methods of computational fluid dynamics, the influence of the number and size of the recesses at their fixed location on the resistance of two types of "Lira" and "Gepard" submarines is investigated. The results show that the decrease in resistance increases with increasing Reynolds number and reaches $6 \%$ for "Lira" with 4 recesses with a diameter of $d=0.01 \mathrm{D}$ at $\operatorname{Re}=1.55 \cdot 108$ and $2 \%$ at $\operatorname{Re}=1.35 .108$ for "Gepard" with 7 recesses with a diameter of $d=0.01 \mathrm{D}$. The effect of the number of cells of the computational grid on the results of calculations in the Flow Simulation (USA, France, Canada) and Flow Vision (Russian Federation) software packages was also studied. The effect of resistance reduction obtained in both software packages is approximately the same, but the absolute values differ due to the small number of cells in Flow Vision, which is due to the limited capabilities of the used 2nd version of this complex. There was also a slight effect of resistance reduction on the model of the "Persia-110" (Iran) submarine with recesses during towing tests in the research basin at significantly lower Reynolds numbers. Unlike most resistance reduction means, the use of this method does not require significant changes in the design of the housing. This makes it possible to use it both on new facilities and on facilities that have already been commissioned

Keywords: submarine, macro-vortex means of reducing motion resistance, computational fluid dynamics
\end{abstract}

Received date 29.07.2020

Accepted date 08.09.2020

Published date 23.10.2020

1. Introduction

It is known that the resistance of submarines at full immersion consists of friction resistance, shape, roughness, cuts,
UDC 629.5.01

DOI: $10.15587 / 1729-4061.2020 .212005$

\section{A STUDY OF THE EFFECT OF RECESSES ON THE MOTION RESISTANCE OF SUBMARINES BY METHODS OF COMPUTATIONAL FLUID DYNAMICS}

J. Bodnarchuk

Postgraduate Student*

E-mail: julka.bodnar4uk@gmail.com

Y u. Korol

$\mathrm{PhD}$, Associate Professor*

E-mail: yuriy.korol@nuos.edu.ua

M. Moones u n

$\mathrm{PhD}$ in Engineering Science, Senior Lecturer

Center for Underwater Research

Malek Ashtar University of Technology

Shahinshahr in Isfahan Iran Isfahan,

Isfahan 17469-37181, Iran

E-mail:m.moonesun@gmail.com

*Educational and Scientific Center Hydromechanics Admiral Makarov National University of Shipbuilding Heroiv Ukrainy ave., 9, Mykolaiv, Ukraine, 54025

\footnotetext{
Copyright (C) 2020,J. Bodnarchuk, Yu. Korol, M. Moonesun This is an open access article under the CC BY license (http://creativecommons.org/licenses/by/4.0)
}

protruding parts, and fencing of retractable devices. Until recently, the only means of determining resistance was a model experiment in research basins. Recalculation of the results of such experiments should be carried out according to the 
rules of similarity of fluid flows using similarity criteria. Such a criterion for submarines in the above case is the Reynolds test. Since it is impossible to achieve equality of Reynolds numbers for the model and nature, in particular for submarines, the recalculation was carried out according to a known approximate empirical scheme. According to this scheme, the coefficient of resistance of the shape was considered independent of the Reynolds number and was determined experimentally. The coefficient of resistance of the other components was considered to be such as the coefficient of friction of the equivalent plate, which was determined by a known empirical dependence on the Reynolds number. This approach is very approximate because it does not take into account the peculiarities of fluid movement in the boundary layer of fullscale objects. Meanwhile, reducing the water resistance for submarines is a very important task, because with constant energy supply increases the range and autonomy, i. e. increases the efficiency of their use. The parameters of the shape of the submarine hull, which are determined during the overall design are compromise and, as a rule, are not optimal in terms of minimum resistance. Based on the analysis of modern literature sources, it is found that the main means of reducing the resistance of submarines are hydrodynamic improvement of the shape of the light hull and a special rubber coating on its surface. Therefore, there is a problem of reducing the resistance of such a case through the development of special methods that do not require adjustment of its size and shape.

\section{Literature review and problem statement}

Analyzing the trends in the study of the hydrodynamics of submarines, it should be noted that many works are devoted to improving the flow around their hull. The results of research based on computational fluid dynamics (CFD) methods are presented in [1-4]. They also evaluate the most important geometric parameters, such as overall bare hull shape, stern shape, bow shape and optimum L/D of the main body. The influence of the parameters of the cylindrical insert on the total resistance and the influence of different shapes of the bow and stern limbs are described. Each of these parameters helps to minimize resistance and increase the hydrodynamic efficiency of the object. In [5, 6], the process of improving the flow on the surface of the housing is described. One of the works proposes the supply of gas bubbles to the surface of the submarine. In $[7,8]$, the flow along the submarine is predicted and corrected with the help of a special rubber coating to reduce resistance and hydroacoustic noise. Prediction of noise dissipated by a submarine is considered here using a non-standard formulation in the frequency domain, which extends the use of acoustic analogy to the problems of scattering. A multi-purpose optimization of the design and shape of the submarine hull is also proposed in [9]. However, in the design of submarines, in addition to the navigability, it is necessary to take into account the influence of other operational factors, so the shape of the hull may differ significantly from the optimal one in terms of navigability. It should also be noted that for military ships, a simple change in the shape of the hull, aimed at reducing resistance, is not enough, so a variety of other methods to reduce resistance are used [10]. Due to the nature of the submarine and its operating environment, most of these methods are not feasible for submarines. A possible solution to the problem could be to use a new method of reducing the resistance of a golf ball, which is to place special recesses - holes on its surface. The studies [11,12] have shown a decrease in golf ball resistance due to the displacement of the point of flow separation downstream. An attempt to replicate this effect on the surface of the vessel, by simulating the surface of a golf ball on the stern of the hull model, is presented in [13]. As a result, the authors concluded that this method was ineffective for ships due to the lack of a significant reduction in resistance. The studies by the authors of this paper have shown [14] that instead of holes on the ship's surface, it is more rational to place cylindrical recesses at right angles to the flow. The effectiveness of the recesses as a means of reducing resistance for a particular vessel depends on the location on the surface, the number, shape and size of their cross-section. In addition, there is a certain range of Reynolds numbers in which recesses can be considered appropriate for a given vessel. The analysis suggests that there is a rather urgent problem of developing means of resistance reduction for submarine hulls designed by compromise technologies. Therefore, it is advisable to install recesses on the surface of the submarine, as one of the means of reducing the resistance of the designed hull. The recesses are located on the surface of the light body, which does not participate in the overall strength. Recesses on the surface of the light body are additional surface stiffeners (frames) and they do not reduce, but rather increase the strength of the light body.

\section{The aim and objectives of the study}

The aim of this work is to determine the location, size and number of circular recesses that reduce the resistance of submarines.

To achieve the aim, the following objectives are set:

- to perform resistance calculations with variations in speed, number, size and location of recesses on the surfaces of submarines;

- to perform the validation process by the method of a submarine model experiment to confirm the correctness of the results obtained with CFD and the feasibility of using recesses on the surface of submarines.

\section{Materials and methods of research}

The subject of the study is the dependence of the resistance of the submarine on the speed and characteristics of the recesses located on its surface which is the object of study. The main research method is to model the motion of full-scale objects in a liquid by numerically solving the RANS equations (Reynolds averaged Navies-Stokes equations). Such modeling is implemented in modern CFD packages, such as Flow Vision (Russian Federation) and Flow Simulation (USA, France, Canada).

Validation of these software products was carried out by comparing the results of calculations with the data of physical experimental studies in $[15,16]$ and showed their very high efficiency and sufficient accuracy for practical use.

The sequence of creating calculation projects for the selected study in these packages is as follows:

1) in the SolidWorks (USA, France, Canada) CAD environment, a 3D model of the research object and the design box that covers it are created;

2) the model of unsteady motion of incompressible fluid and the $k$ - $\varepsilon$ turbulence model are chosen; 
3) initial conditions are determined (temperature and type of liquid medium and initial velocities or pressure);

4) boundary conditions are formed on the surface of the design box and the research object;

5 ) the global computational grid and the level of refinement of the local computational grid on the surface of the research object are generated;

6 ) in the postprocessor, computation purposes and visualization parameters of computation results are formed.

To focus on the processes of flow around the hulls and reduce the cost of computer resources, the following study considered submarines without protruding parts. Fig. 1 shows a 3D model of such a submarine, located in the design box, the minimum size of which was thus reduced to 3 lengths and 5 diameters of its hull. Also Fig. 1 shows the layout of boundary conditions for all projects. The inlet flow rate is set at the inlet, the free outlet condition is set at the outlet, and symmetry is set on the sidewall of the box, which means that there is no viscous component of the fluid movement on it. On the surface of the submarine hull - the condition of a solid impenetrable wall.

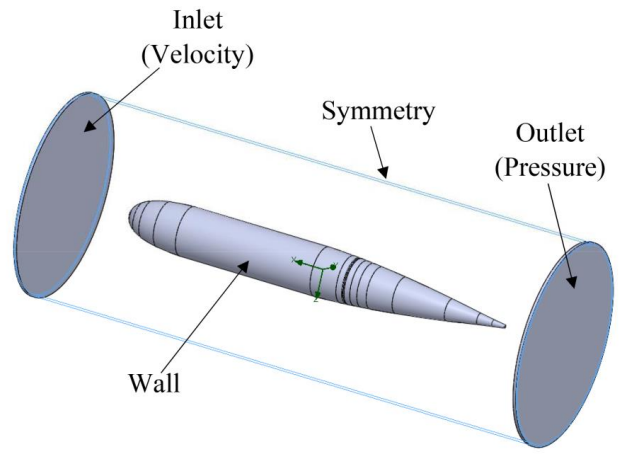

Fig. 1. Layout of boundary conditions on the surface of the design box and submarine

The results of CFD modeling are significantly affected by the number of cells in the computational grid. Therefore, before performing variant calculations, a study of the influence of the level of fragmentation of the global and local grid on the surface on the result of calculations was performed. Particular attention was paid in the area of the recesses, as the large size of the grid cell does not allow correct calculation of the processes inside the recesses. It was found that for the Flow Simulation package, the level of refinement of the global grid should be at least 4, and the local grid on the surface of the submarine should also be at least 4 . The total number of cells ranges from 1.5 to 1.7 million.

In the Flow Vision software package, the number of cells can be reduced to 1 million due to a special method of local grid adaptation. However, given the technical capabilities of the second 32-bit version of this package, practical use is limited to 500-750 thousand cells.

\section{Calculations of resistance for variations in} the parameters of recesses on the surfaces of submarines

5. 1. Calculations of resistance for variations in speed, number, size and location of recesses on the surfaces of submarines

During movement, the submarine drives the mass of surrounding water and undergoes a hydrodynamic reaction on the surface of the hull. In the general case, the resistance depends on the main dimensions, coefficients of completeness, shape of the contours, condition of the hull surface, speed and motion conditions of the submarine. Water resistance is considered separately for underwater, surface, as well as for the periscope positions of the submarine due to the peculiarities of the formation of hydrodynamic forces in each of these modes. The total resistance to movement in the underwater position [17] consists of: friction $\approx 54 \%$, roughness $\approx 10 \%$, cuts $\approx 5 \%$, shape $\approx 10 \%$, protruding parts $\approx 12 \%$, fencing of retractable devices $\approx 9 \%$. Therefore, this study considers the reduction of the main components of the bare body, namely friction and shape by installing regulators of the thickness of the boundary layer in the form of special recesses. A macro-vortex flow is formed in the recesses inside which the pressure is significantly reduced. This phenomenon leads to a decrease in the thickness of the boundary layer. As a result, the friction resistance and viscous pressure (shape) resistance decrease due to the displacement of the separation zone downstream and the creation of a smaller area of low pressure behind the body. With the right choice of location, shape and number of recesses, the pressure on the surface of the object is redistributed, which can lead to a decrease in the total resistance of the submarine. The influence of recesses on the formation of a hydrodynamic trail behind the submarine is shown in Fig. 2.

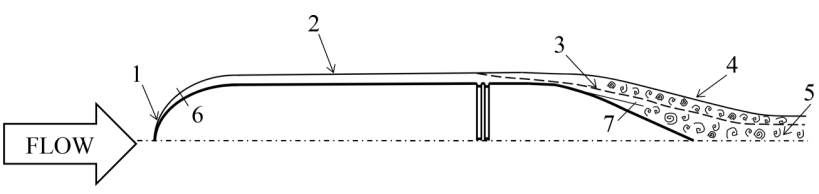

Fig. 2. Formation of layers on the surface of the submarine: 1 - laminar boundary layer; 2 - turbulent boundary layer;

3 - hydrodynamic trail of the submarine with recesses;

4 - hydrodynamic trail of the submarine; 5 - vortex; 6 - transition; 7 - separation

To study the efficiency of recesses on the surface of submarines, two solid body models of the "Lira" and "Gepard" hulls were created in the SolidWorks CAD system (Fig. 3, 4). The models were created without felling and rudders to reduce calculation time. The main characteristics of the selected submarines are given in Tables 1, 2.

Table 1

"Lira" submarine

\begin{tabular}{|c|c|}
\hline Surface (underwater) displacement & $\nabla=2,300(3,100)$ tons \\
\hline Length & $L=81.4 \mathrm{~m}$ \\
\hline Diameter & $D=10 \mathrm{~m}$ \\
\hline Maximum speed & $v=42 \mathrm{knots}$ \\
\hline Wet surface area & $S=2,029 \mathrm{~m}^{2}$ \\
\hline
\end{tabular}

Table 2

"Gepard" submarine

\begin{tabular}{|c|c|}
\hline Surface (underwater) displacement & $\nabla=6,430(8,140)$ tons \\
\hline Length & $L=110.3 \mathrm{~m}$ \\
\hline Diameter & $D=13.6 \mathrm{~m}$ \\
\hline Maximum speed & $v=33 \mathrm{knots}$ \\
\hline Wet surface area & $S=3,932 \mathrm{~m}^{2}$ \\
\hline
\end{tabular}




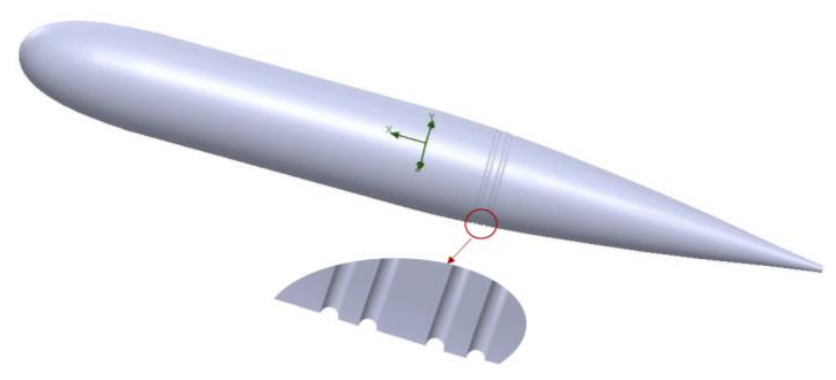

Fig. 3. Model of the "Lira" type submarine with recesses

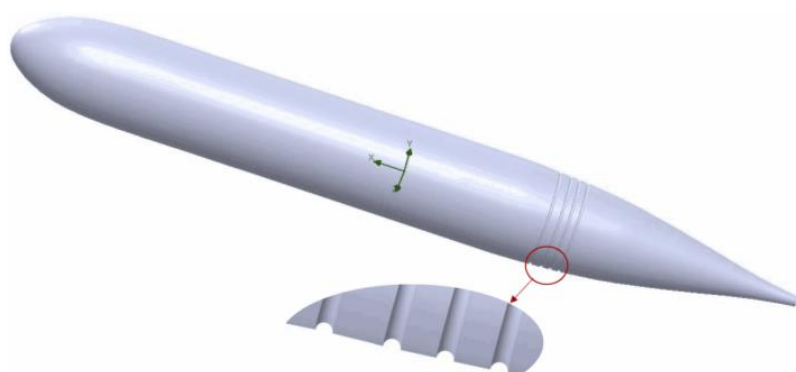

Fig. 4. Model of the "Gepard" type submarine with recesses

The distribution of velocities and pressure inside and around the 4 recesses that were installed on the surface of the "Lira" type submarine are shown in Fig. 5, 6. It is clear that in the recesses a macro-vortex is formed, in which there is a marked decrease in pressure. The choice of the number, size and location of the recesses is very important, as the wrong choice can lead to deterioration of the flow conditions and increased resistance.

When flowing around bodies with large Reynolds numbers Re, the phenomenon of separation of the boundary layer is observed, which leads to an increase in the diameter of the hydrodynamic trace and to an increase in resistance. The recesses, which are located in the area of the separation points, reduce the boundary layer due to the reduced pressure inside the recesses. Due to this, the separation points are shifted to the stern limb, and the diameter of the hydrodynamic trail decreases.

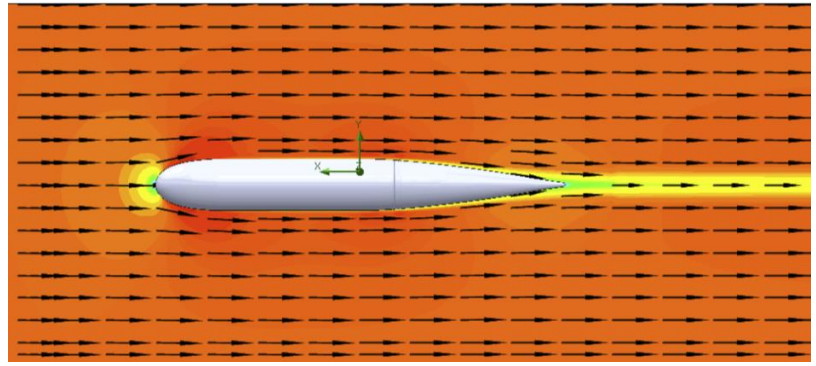

$a$

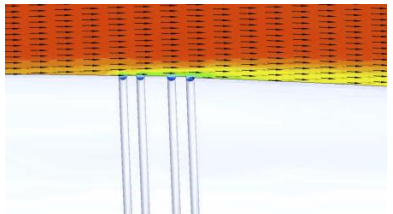

b

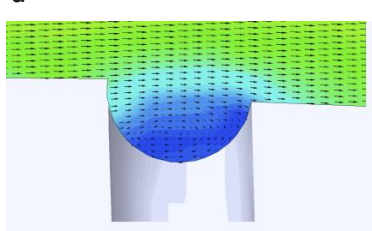

$c$
Fig. 5. Pressure and velocity distribution: $a-$ velocity distribution around the recesses; $b$ - vortex velocity inside the recess; $c$ - pressure distribution on the surface in the area of the recesses

Based on the results of calculations, graphs were constructed (Fig. 7,8) which show the efficiency of annular recesses of different diameters $d$ with a fixed location relative to the smooth bodies. The resistance coefficients $C_{x}$ and the Reynolds number Re were calculated by the formulas:

$$
C_{x}=\frac{2 R_{x}}{\rho v^{2} S}
$$

where $R_{x}$ is the resistance of the submarine, $\mathrm{N} ; \rho$ is water density, $\mathrm{kg} / \mathrm{m}^{3}$; $v$ is the speed of the submarine, $\mathrm{m} / \mathrm{s} ; S$ is the area of the wetted surface, $\mathrm{m}^{2}$,

$$
\operatorname{Re}=\frac{v_{x} D}{v}
$$

where $v_{x}$ is the speed of the submarine, $\mathrm{m} / \mathrm{s} ; \boldsymbol{v}=1.3 \cdot 10^{-6} \mathrm{~m}^{2} / \mathrm{s}$ is the kinematic viscosity coefficient of the liquid; $D$ is the diameter of the submarine, $\mathrm{m}$.

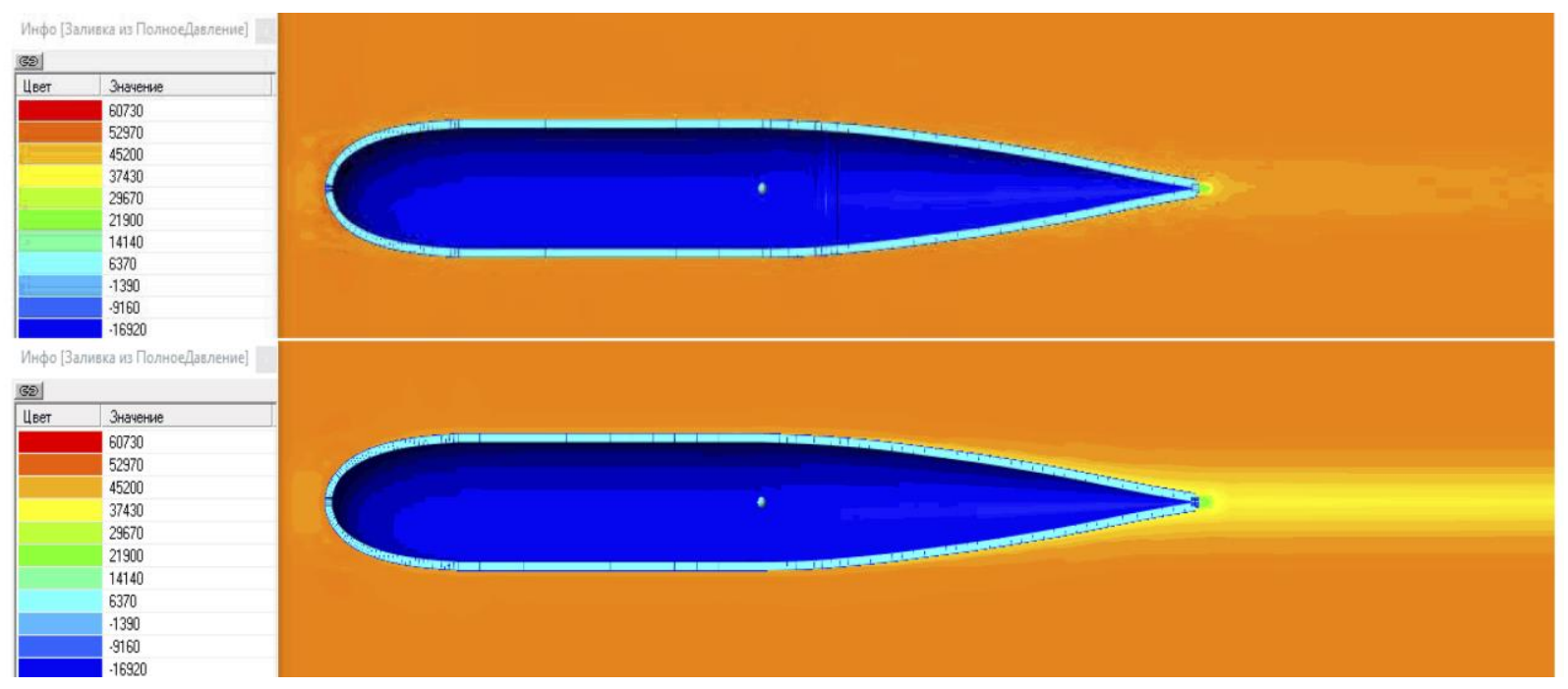

Fig. 6. Pressure distribution around the "Lira" type submarine, with and without recesses 


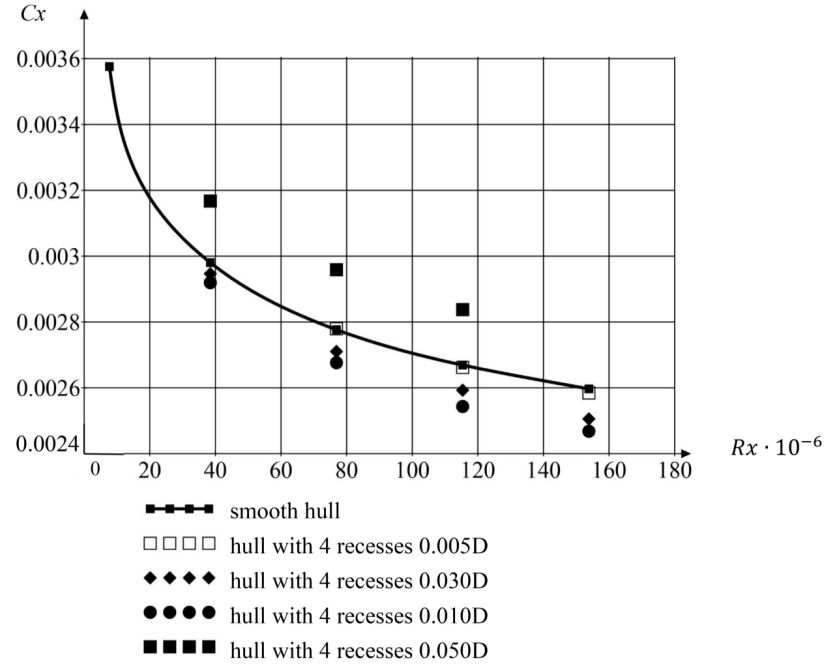

Fig. 7. Graph of the dependence of the resistance coefficient $C_{x}$ on the Reynolds number Re and diameter of the recesses $d$ for the "Lira" type submarine

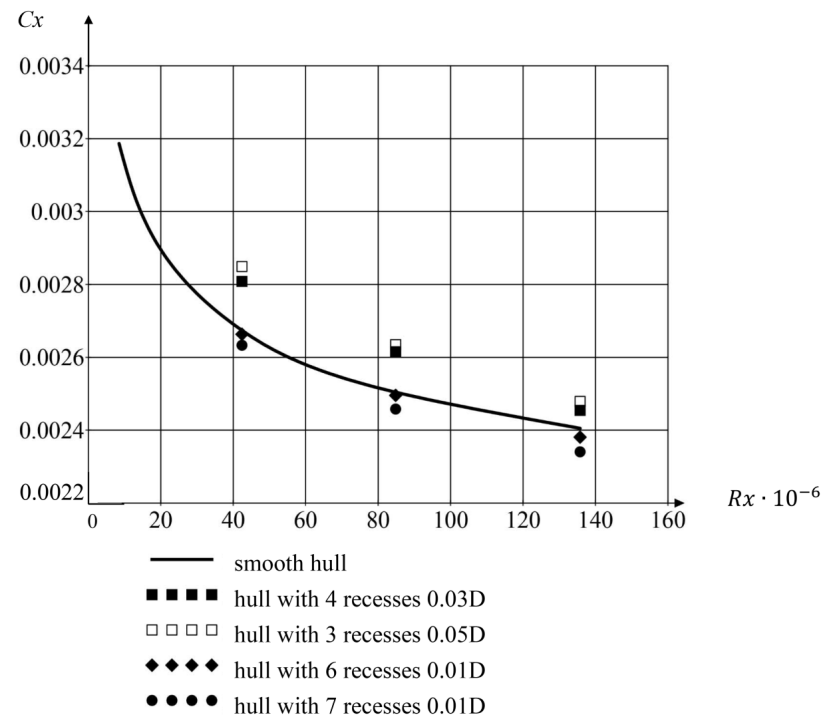

Fig. 8. Graph of the dependence of the resistance coefficient $C_{x}$ on the Reynolds number Re, diameter $d$ and number of recesses for the "Gepard" type submarine
From the hydrodynamic point of view, the shape of the hull of the "Gepard" submarine is more perfect, as at equal Reynolds numbers, the total resistance coefficient of "Gepard" is less than that of "Lira", despite the fact that the displacement coefficient of "Lira" $C_{D}=0.485$ and "Gepard" $C_{D}=0.508$

Given the exceptional complexity of the phenomena of hydrodynamic interaction of the recesses with the hull of the submarine in each case, it is necessary to perform variant calculations of the influence of the parameters of the recesses on the resistance coefficients and thus assess their effectiveness.

Visualization of the pressure distribution on the surface of the research objects presented in Fig. 9, 10 in the first approximation helps to assess the location of the recesses and determine the number of calculation options.

A comparison of the results of calculations of the "Lira" type submarine was performed in the two software packages Flow Vision and Flow Simulation, which are presented in Table 3.

Table 3

Results of the calculation of the "Lira" type submarine in the Flow Vision and Flow Simulation software packages

\begin{tabular}{|c|c|c|c|c|}
\hline \multirow{4}{*}{$V, \mathrm{~m} / \mathrm{s}$} & $\begin{array}{c}\text { "Lira" type submarine with } \\
\text { a smooth hull }\end{array}$ & $\begin{array}{c}\text { "Lira" type submarine with } \\
\text { 4 0.03 D recesses }\end{array}$ \\
\cline { 2 - 5 } & \multicolumn{2}{|c|}{ Number of cells in the computational grid } \\
\cline { 2 - 5 } & $1,621,324$ & 185,699 & $1,692,405$ & 328,801 \\
\cline { 2 - 5 } & $\begin{array}{c}\text { Flow } \\
\text { Simulation }\end{array}$ & Flow Vision & $\begin{array}{c}\text { Flow } \\
\text { Simulation }\end{array}$ & Flow Vision \\
\cline { 2 - 5 } & \multicolumn{4}{|c|}{ Cx } \\
\hline 1 & 0.003576 & 0.003283 & - & - \\
\hline 5 & 0.002980 & 0.002808 & 0.002947 & 0.002775 \\
\hline 10 & 0.002776 & 0.002380 & 0.002710 & 0.002323 \\
\hline 15 & 0.002669 & 0.002566 & 0.002593 & 0.002492 \\
\hline 20 & 0.002597 & 0.002509 & 0.002506 & - \\
\hline
\end{tabular}

The number of cells of the computational grid given in Table 3 for Flow Simulation is determined by the results of special numerical experiments. These experiments consist in increasing the number of cells successively until the resistance of the submarine ceases to change.

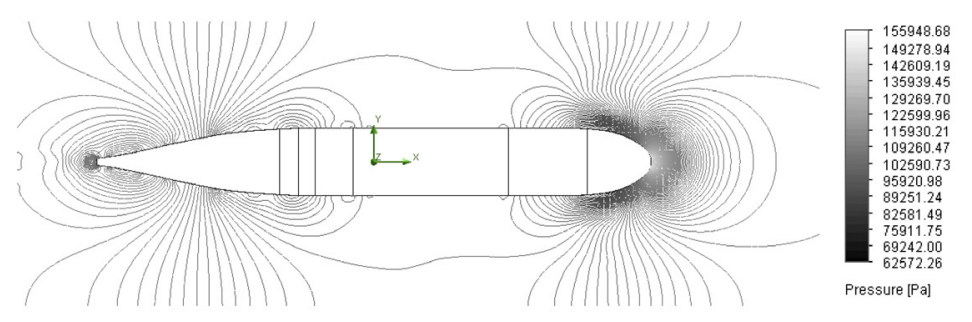

Fig. 9. Pressure distribution on the surface of the submarine

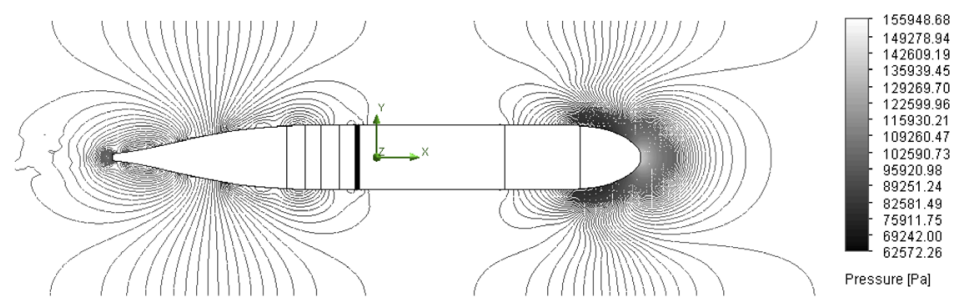

Fig. 10. Pressure distribution on the surface of the submarine with installed recesses 
Thus, it is found that the 4th level of refinement of the global and local grids is sufficient and corresponds to the number of cells listed in the table. However, determining the required number of cells in this way for Flow Vision leads to almost unacceptable calculation time, because the capabilities of the 2nd single-processor 32-bit version of this product are extremely limited. But the results in this table, obtained in both software products, indicate the unconditional effect of the recesses on the resistance of the submarine in the direction of its reduction.

\section{2. Process of validation by the method of a model} experiment of a submarine

The process of validation of calculations to confirm the correctness of the results obtained with CFD and the feasibility of using recesses on the surface of submarines was performed.

To test the possibility and feasibility of using the recesses, an experiment was conducted with towing a model of a torpedo-shaped underwater object of the Persia-110 type. The experiment was performed in the research basins of the Admiral Makarov National University of Shipbuilding (NUS) (Ukraine) and the Isfahan branch of the Maleke Ashtar University of Science and Technology (UST) (Iran). The general shape and dimensions of this model are shown in Fig. 11-13. The model has a volume of 8.38 liters, a total area of $0.36 \mathrm{~m}^{2}$, weight $8.38 \mathrm{~kg}$. The $L / D$ ratio is 13 , which is within the normal $L / D$ of large naval submarines.

The experiment was conducted in two stages: at the first stage, the NUS performed an experiment on a model without recesses. At the second stage, in UST with $40.01 \mathrm{D}$ recesses (similar to Fig. 7 case 4). The results are presented in Table 4.

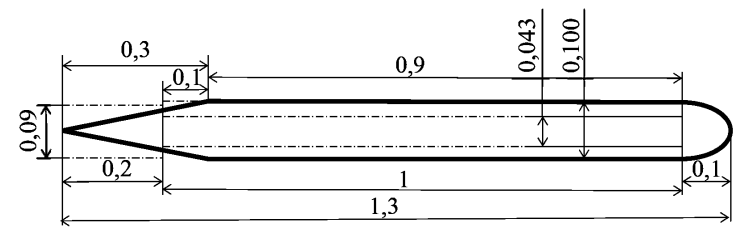

Fig. 11. Dimensions of the Persia-110 model

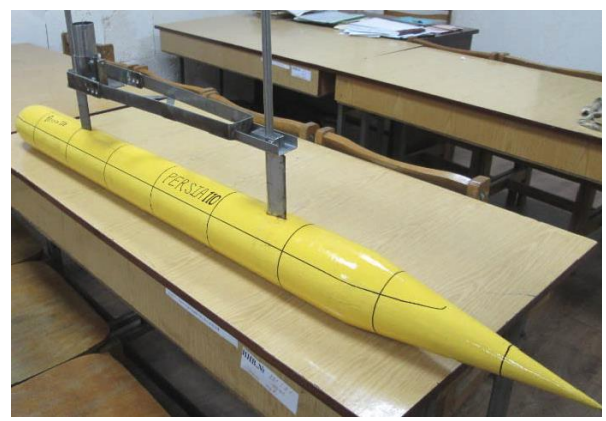

Fig. 12. General view of the Persia-110 model

The obtained results confirm the presence of the effect of resistance reduction due to the installation of recesses on the surface of Persia-110. The effect of the installed recesses depends on the following factors: location of the recesses, shape and size according to the length of the submarine and Reynolds number. Given that the Reynolds numbers are very small, for a noticeable effect of resistance reduction, the size of the recesses will be relatively larger than for nature. There is no practical value of the obtained model calculations because they cannot be transferred to a full-scale object.

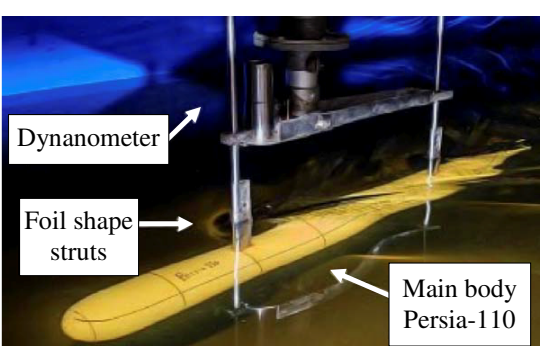

Fig. 13. Persia-110 model during tests in the research basin of NUS

Table 4

Results of the Persia-110 experiment model

\begin{tabular}{|c|c|c|c|c|}
\hline$v,(\mathrm{~m} / \mathrm{s})$ & $\mathrm{Re} \cdot 10^{-6}$ & $\begin{array}{c}\text { No recesses } \\
R_{x}(N)\end{array}$ & $\begin{array}{c}\text { With recess- } \\
\text { es } R_{x}(N)\end{array}$ & $\begin{array}{c}\% \text { Reduc- } \\
\text { tion }\end{array}$ \\
\hline 1 & 0.0769 & 1.873 & 1.864 & 0.5 \\
\hline 1.2 & 0.0923 & 2.726 & 2.707 & 0.7 \\
\hline 1.5 & 0.1154 & 4.288 & 4.245 & 1 \\
\hline 2 & 0.1539 & 7.831 & 7.696 & 1.7 \\
\hline
\end{tabular}

\section{Discussion of the results of studying the influence of recesses on the resistance of submarines}

Within the framework of this work, a study of the influence of recesses on the surface of two types of submarines was performed. According to the obtained results, it is confirmed that the installation of recesses decreases the thickness of the boundary layer and leads to a decrease in the thickness of the hydrodynamic trace, which can be observed in Fig. 6. This is due to the fact that in the recesses a macro-vortex is formed (Fig. 5), in which there is a marked decrease in pressure. The results of calculations showed (Fig. 7,8) that with the correct choice of size, location and number of recesses, it is possible to achieve a reduction in resistance by $2-5 \%$. For the "Lira" type submarine, all hulls have four recesses. For diameters of $0.01 D$ and $0.03 D$, the best efficiency is obtained, and for the diameter of $0.05 \mathrm{D}$, the worst efficiency is obtained and leads to an increase in resistance. Different numbers of recesses are considered for the "Gepard" type submarine. The installation of 7 recesses with $0.01 D$ has the best efficiency, and the location of four recesses with a diameter of $0.03 \mathrm{D}$ and the location of three recesses with a diameter of $0.05 \mathrm{D}$ have the lowest efficiency. In contrast to the study [14], in which the stern of the vessel is covered with recesses imitating the surface of a golf ball, we propose to install several annular recesses, which greatly simplifies the design. An experimental test of the Persia-110 model with installed recesses was also performed, which confirmed the correctness of the calculations (Table 4). Given that the Reynolds numbers of the model experiment are very small, the effect itself is small, and its practical value is absent, because these results cannot be translated into a full-scale object. That is, model experiments can only confirm the presence of the effect, and the parameters of the recesses can be calculated only in CFD packages for full-scale objects. As a result, there is another problem with the quality of software products to ensure high accuracy of calculations. The advantage of using this method is that, unlike most resistance reduction means, the use of this method does not require significant changes in the design of the housing. This makes it possible to use it both on new facilities and on facilities that have already been commissioned. Despite the 
advantages, the studies have shown that the incorrect size, location and number of recesses can lead to increased resistance. It is not possible to develop general recommendations for the location, size and number of recesses for all submarines. These parameters are determined for each submarine by separate calculations. Further development of the study is to determine the effect on reducing the resistance of the shape of the recesses in combination with other parameters.

\section{Conclusions}

1. Analysis of the obtained resistance results with variations in speed, number, size and location of recesses on the surfaces of submarines showed that it is possible to achieve a reduction in resistance by $2-5 \%$. Namely, for "Lira", the most effective were excavations with a diameter of $d=0.01 D$, which allowed a gradual decrease in the resistance coefficient from $0 \%$ at $\operatorname{Re}=10^{7}$ to $6 \%$ at $\operatorname{Re}=1.5 \cdot 10^{8}$ for four recesses. For "Gepard", the most effective were recesses of the same diameter $d=0.01 D$, but their number increased to 7 , and the efficiency does not exceed $2 \%$ at $R e=1.35 \cdot 10^{8}$. For both submarines, the use of recesses with $d=0.05 D$ leads to additional resistance and an increase in resistance coefficients in the entire range of Reynolds numbers.
2. The effect of the installed recesses depends on the following factors: the location of the recesses; shape and size according to the length of the submarine and the Reynolds number. Given that the Reynolds numbers are very small, for a noticeable effect of resistance reduction, the size of the recesses will be relatively larger than for nature. There is no practical value of the obtained model calculations because they cannot be transferred to a fullscale object.

\section{Acknowledgments}

We thank the leadership of the Admiral Makarov National University of Shipbuilding for participation in two state-funded research works. The first work "Improving the efficiency and reliability of small and high-speed metal vessels" adopted by the Ministry of Education and Science, Youth and Sports of Ukraine from 25.09.2013 state registration number No. 0113U000244, topic number 1897. The second work "Development of methodology for improving the efficiency and safety of the river transport system of Ukraine" adopted by the Ministry of Education and Science of Ukraine on October 25, 2017, state registration number No. 0117U000347, topic number 2085.

\section{References}

1. Moonesun, M., Korol, Y. M., Dalayeli, H. (2015). CFD Analysis on the Bare Hull Form of Submarines for Minimizing the Resistance. International Journal of Maritime Technology, 3, 1-16. Avaialble at: http://ijmt.ir/files/site1/user_files_13d531/moonesunA-10-450-1-97a2052.pdf

2. Moonesun, M., Korol, Y. M., Brazhko, A. (2015). CFD analysis on the equations of submarine stern shape. Journal of Taiwan Society of Naval Architects and Marine Engineers, 34 (1), 21-32. Avaialble at: https://www.researchgate.net/publication/283106187 CFD_analysis_on_the_equations_of_submarine_stern_shape

3. Moonesun, M., Korol, Y. M., Nikrasov, V. A., Ursalov, A., Brajhko, A. (2016). CFD analysis of the bow shapes of submarines. Journal of Scientific and Engineering Research, 3 (1), 1-16. Avaialble at: https://www.researchgate.net/publication/331001130_CFD_ analysis_of_the_bow_shapes_of_submarines

4. Moonesun, M., Mahdian, A., Korol, Y. M., Dadkhah, M., Javadi, M. M., Brazhko, A. (2016). Opti mum L/D for Submarine Shape. Indian Journal of Geo-Marine Sciences, 45 (1), 38-43. Avaialble at: https://pdfs.semanticscholar.org/0bb4/68b6b618d564c401285ecf31129312e677a2.pdf

5. Anthony, S. (2014). China's supersonic submarine, which could go from Shanghai to San Francisco in 100 minutes, creeps ever closer to reality. ExtremeTech. Avaialble at: https://www.extremetech.com/extreme/188752-chinas-supersonic-submarine-which-couldgo-from-shanghai-to-san-francisco-in-100-minutes-creeps-ever-closer-to-reality\#: :text=Researchers\%20in\%20China\%20are\%20 reporting,miles\%20\%E2\%80\%94\%20in\%20just\%20100\%20minutes

6. Kukner, A., Duran, A., Cinar, T. (2016). Investigation of flow distribution around a submarine. Journal of Naval Science and Engineering, 12 (2), 1-26. Avaialble at: https://www.researchgate.net/publication/313253877_INVESTIGATION_OF_FLOW_ DISTRIBUTION_AROUND_A_SUBMARINE

7. Testa, C., Greco, L. (2018). Prediction of submarine scattered noise by the acoustic analogy. Journal of Sound and Vibration, 426 , 186-218. doi: https://doi.org/10.1016/j.jsv.2018.04.011

8. Wang, L. (2017). Numerical Analysis of Wake Field over a Submarine with Full Appendages Based on STAR-CCM+. DEStech Transactions on Materials Science and Engineering, (icmsea/mce). doi: https://doi.org/10.12783/dtmse/icmsea/mce2017/10852

9. Mora Paz, J. D., Tascón Muñoz, O. D. (2014). Multiobjective Optimization of a Submarine Hull Design. Ciencia y Tecnología de Buques, 7 (14), 27. doi: https://doi.org/10.25043/19098642.92

10. Ahmadzadehtalatapeh, M., Mousavi, M. (2015). A Review on the Drag Reduction Methods of the Ship Hulls for Improving the Hydrodynamic Performance. International Journal of Maritime Technology, 4, 51-64. Avaialble at: http://ijmt.ir/browse.php?a id $=428 \&$ slc_lang $=$ en $\&$ sid $=1 \&$ printcase $=1 \&$ hbnr $=1 \&$ hmb $=1$

11. Aoki, K., Muto, K., Okanaga, H., Nakayama, Y. (2009). Aerodynamic characteristic and flow pattern on dimples structure of a sphere. 10th International Conference on Fluid Control, Measurements and Visualization. Avaialble at: http://www.ihed.ras.ru/ flucome10/cd/papers/221.pdf

12. Tai, C.-H., Leong, J.-C., Lin, C.-Y. (2007). Effects of golf ball dimple configuration on aerodynamics, trajectory, and acoustics. Journal of Flow Visualization and Image Processing, 14 (2), 183-200. doi: https://doi.org/10.1615/jflowvisimageproc.v14.i2.40

13. Donnelly, K. J. (2009). Reduction of Ship Resistance through Induced Turbulent Boundary Layers. Melbourne, 74. Avaialble at: http:// my.fit.edu/ swood/Reduction\%20of\%20Ship\%20Resistance\%20through\%20Induced\%20Turbulent\%20Boundary\%20Layers.pdf 
14. Korol, Yu. M., Bodnarchuk, Yu. S. (2018). Pat. No. 134146 UA. Sposib rehuliuvannia rozpodilu tysku na zmocheniy poverkhni sudna. No. u201808745; declareted: 15.08.2018; published: 10.05.2019, Bul. No. 9.

15. Praveen, P., Krishnankutty, P. (2013). Study on the effect of body length on the hydrodynamic performance of an axi-symmetric underwater vehicle. Indian Journal of Geo-Marine Sciences, 42 (8), 1013-1022. Avaialble at: https:/ www.researchgate.net/publication/289737121 Study_on_the_effect_of_body_length_on_the_hydrodynamic_performance_of_an_axi-symmetric_underwater_vehicle

16. Vali, A., Saranjam, B., Kamali, R. (2018). Experimental and Numerical Study of a Submarine and Propeller Behaviors in Submergence and Surface Conditions. Journal of Applied Fluid Mechanics, 11 (5), 1297-1308. doi: http://doi.org/10.29252/jafm.11.05.28693

17. Hodkost' podvodnyh lodok. Avaialble at: https://znatock.org/s69t1.html

A three-mass anti-resonance vibratory machine with a vibration exciter in the form of a passive auto-balancer has been analytically synthesized. In the vibratory machine, platforms 1 and 2 are viscoelastically attached to platform 3. Platform 3 is visco-elastically attached to the base. The motion of loads relative to the auto-balancer housing is hindered by the forces of viscous resistance.

A theoretical study has shown that the vibratory machine possesses three resonance frequencies and three corresponding forms of platforms' oscillations. Values for the parameters of supports that ensure the existence of an anti-resonance form of motion have been analytically selected. Under an anti-resonance form, platform 3 is almost non-oscillating while platforms 1 and 2 oscillate in the opposite phase.

In the vibratory machine, platform 1 can be active (working), platform 2 will then be reactive (a dynamic vibration damper), and vice versa. At the same time, the vibratory machine will operate when mounting a vibration exciter both on platform 1 and platform 2.

An anti-resonance form would occur when the loads get stuck in the vicinity of the second resonance frequency of the platforms' oscillations.

Given the specific parameters of the vibratory machine, numerical methods were used to investigate its dynamic characteristics. Numerical calculations have shown the following for the case of small internal and external resistance forces in the vibratory machine:

- theoretically, there are seven possible modes of load jam;

- the second (anti-resonance) form of platform oscillations is theoretically implemented at load jamming modes 3 and 4;

- jamming mode 3 is locally asymptotically stable while load jamming mode 4 is unstable;

- for the loads to get stuck in the vicinity of the second resonance frequency, one needs to provide the vibratory machine with the initial conditions close to the jamming mode 3, or smoothly accelerate the rotor to the working frequency;

- the dynamic characteristics of the vibratory machine can be controlled in a wide range by changing both the rotor speed and the external and internal forces of viscous resistance.

The results reported here are applicable for the design of anti-resonance three-mass vibratory machines for general purposes

Keywords: inertial vibration exciter, resonance vibrations, anti-resonance vibratory machine, auto-balancer, three-mass vibratory machine, Sommerfeld effect
UDC 622.74: 621.928.235

DOI: $10.15587 / 1729-4061.2020 .213724$

RESEARCH OF ANTIRESONANCE THREEMASS VIBRATORY MACHINE WITH A VIBRATION EXCITER IN THE FORM OF A PASSIVE AUTO-BALANCER

\author{
V. Y a t su n \\ $\mathrm{PhD}$, Associate Professor \\ Department of Road Cars and Building *** \\ G. F i li mo n i k h i n \\ Doctor of Technical Sciences, \\ Professor, Head of Department* \\ E-mail: filimonikhin@ukr.net \\ V. P i r o g o v \\ $\mathrm{PhD}$, Senior Lecturer* \\ V. A mos o v \\ PhD, Associate Professor** \\ P. L u z a n \\ $\mathrm{PhD}$, Associate Professor \\ *Department of Machine Parts and \\ Applied Mechanics*** \\ **Department of \\ Agricultural Machine Building*** \\ $\star * \star$ Central Ukrainian National Technical University \\ Universytetskyi ave., 8, Kropyvnytskyi, \\ Ukraine, 25006
}

Received date 14.09.2020

Accepted date 05.10.2020

Published date 23.10.2020
Copyright (C) 2020, V. Yatsun, G. Filimonikhin, V. Pirogov, V. Amosov, P. Luzan This is an open access article under the CC BY license (http://creativecommons.org/licenses/by/4.0)

\section{Introduction}

Resonance vibratory machines are promising as regards the vibratory machines for various applications [1]. In them, vibration exciters of smaller mass excite oscillations with a greater amplitude, which improves the reliability and durability of vibratory machine operation.

The most effective and simple techniques to excite resonance oscillations are based on the use of the Sommerfeld effect [2-12]. Among these techniques, of special relevance 